\title{
A human monoclonal autoantibody to breast cancer identifies the PDZ domain containing protein GIPCI as a novel breast cancer-associated antigen
}

\author{
Sergei Rudchenko1, Matthew Scanlan², Gavreel Kalantarov³, \\ Victoria Yavelsky ${ }^{4}$, Chen Levy ${ }^{4}$, Alison Estabrook ${ }^{3}$, Lloyd Old ${ }^{2}$, \\ Gerald L Chan ${ }^{5}$, Leslie Lobel ${ }^{\dagger 4}$ and Ilya Trakht* ${ }^{*} 3$
}

\begin{abstract}
Address: ${ }^{1}$ Hospital for Special Surgery, 535 East 70th Street, New York NY 10021, USA, ${ }^{2}$ Ludwig Institute for Cancer Research, New York Branch at Memorial Sloan-Kettering Cancer Center, 1275 York Avenue, New York, NY 10021, USA, ${ }^{3}$ College of Physicians and Surgeons, Columbia University, 630 W. 168 St., New York, NY 10032, USA, ${ }^{4}$ Department of Virology, Faculty of Health Sciences, Ben Gurion University of the Negev, Beer Sheva 84105, Israel and ${ }^{5}$ The Morningside Foundation, 1188 Centre Street, Newton Centre, MA 02459, USA

Email: Sergei Rudchenko - RudchenkoS@HSS.EDU; Matthew Scanlan - Scanlan_Matthew/mskcc_HN@mskmail.mskcc.org;

Gavreel Kalantarov - gfk1@columbia.edu; Victoria Yavelsky - yavelsky@bgu.ac.il; Chen Levy - levyche@gmail.com;

Alison Estabrook - ae9@columbia.edu; Lloyd Old - lold@licr.org; Gerald L Chan - glchan@morningside.com; Leslie Lobel - llobel@bgu.ac.il; Ilya Trakht* - it8@columbia.edu

* Corresponding author †Equal contributors
\end{abstract}

Published: 24 August 2008

BMC Cancer 2008, 8:248 doi:10.1 I86/I47I-2407-8-248

This article is available from: http://www.biomedcentral.com//47/-2407/8/248

(C) 2008 Rudchenko et al; licensee BioMed Central Ltd.

This is an Open Access article distributed under the terms of the Creative Commons Attribution License (http://creativecommons.org/licenses/by/2.0), which permits unrestricted use, distribution, and reproduction in any medium, provided the original work is properly cited.

\begin{abstract}
Background: We have been studying the native autoimmune response to cancer through the isolation of human monoclonal antibodies that are cancer specific from cancer patients. To facilitate this work we previously developed a fusion partner cell line for human lymphocytes, MFP-2, that fuses efficiently with both human lymph node lymphocytes and peripheral blood lymphocytes. Using this unique trioma fusion partner cell line we isolated a panel of autologous human monoclonal antibodies, from both peripheral blood and lymph node lymphocytes, which are representative of the native repertoire of anti-cancer specific antibodies from breast cancer patients.
\end{abstract}

Methods: The current study employs immunocytochemistry, immunohistochemistry, Western blot analysis as well as Northern blots, Scatchard binding studies and finally SEREX analysis for target antigen identification.

Results: By application of an expression cloning technique known as SEREX, we determined that the target antigen for two monoclonal antibodies, 27.BI and 27.F7, derived from lymph node Bcells of a breast cancer patient, is the PDZ domain-containing protein known as GIPCI. This protein is highly expressed not only in cultured human breast cancer cells, but also in primary and metastatic tumor tissues and its overexpression appears to be cancer cell specific. Confocal microscopy revealed cell membrane and cytoplasmic localization of the target protein, which is consistent with previous studies of this protein.

Conclusion: We have determined that GIPCI is a novel breast cancer-associated immunogenic antigen that is overexpressed in breast cancer. Its role, however, in the initiation and/or progression of breast cancer remains unclear and needs further clarification. 


\section{Background}

In patients with cancer, the body mounts an immune response following the onset of malignant disease since the new cells are recognized as non-self. It is composed of both immune cells that mediate innate, non-specific immunity, and adaptive, antigen-specific immunity [1-3]. Tumor cell proteins can elicit an immune response for various reasons; aberrant gene expression (e.g. cancer-testis antigens) [4-10], overexpression (neu/Her2) [11,12], aberrant processing (mucin) $[13,14]$ and mutation events (p53) $[11,15]$. Although it is evident that a natural humoral response to cancer exists, tumor-associated antigens (TAAs) are generally notoriously bad immunogens. This is likely due to systemic tolerance to the autoantigens and, as a result, the natural humoral immune response against tumor antigens fails to reach high antibody titers and is not effective [16].

During the last decade, the search for TAAs that can be targeted by the immune system, and as such are "immunovisible", has been the focus of much research in cancer immunology. In addition, the isolation and production of fully human monoclonal antibodies (fhMAb) to such antigens has also made significant advances over the past few years [16-18]. The potential utility of these antibodies to identify TAAs, to discriminate between neoplastic and normal tissues and potentially act as anti-cancer therapeutics has been the impetus for this work.

To identify tumor-associated antigens, one of the more fruitful approaches has been to employ naturally occurring anti-cancer antibodies that arise in cancer patients. To this end, serological expression technology (SEREX) has facilitated the identification of novel TAAs by screening patients' whole sera on cDNA expression libraries that were prepared from autologous tumors or human cancer cell lines [19-23]. This technology has led to the creation of a database of protein antigens that are associated with and specific to a variety of cancers. However, the native immune response to these antigens is not identified or captured by this methodology. Therefore, although proteins that are associated specifically with cancer can be pinpointed, the antibodies that can effectively target these antigens remain mostly unidentified.

To overcome this limitation we designed and implemented an alternate strategy that relies on a unique trioma fusion partner cell line, MFP-2, which we developed [24]. MFP-2 can efficiently fuse with both peripheral blood and lymph node lymphocytes. Following fusion, surviving hybridoma clones are stable for prolonged periods and many produce significant quantities of human monoclonal antibodies. We employed this unique fusion partner cell line to develop a panel of native autologous fully human monoclonal antibodies (fhMAb) that were culled from the natural repertoire arising in breast cancer patients [25]. These fhMAbs reacted specifically with breast cancer cells and malignant tissues. They are useful not only for identification of the target antigens, but also for immunodiagnostic procedures [26] and eventually for immunotherapy of breast cancer, since they can be produced on an industrial scale.

We identified the protein targets of two of the anti-breast cancer autoantibodies that we isolated, and determined that they target the protein GIPC1. Using our fhMAbs that target GIPC1, we studied its expression in human breast tissue and in cultured cells. We determined that this protein is specifically up-regulated in malignant breast epithelial tissue/cells and in breast cancer cell lines and is not detected in normal breast epithelia or in live primary fibroblast cell lines. Therefore, GIPC1 is a novel breast cancer-associated antigen that may play a role in the initiation and/or progression of breast cancer.

\section{Methods \\ Cell culture}

All human cancer and normal cell lines were purchased from ATCC. Human breast cancer cell lines MCF-7 and SK-BR-3 and primary human fibroblasts are among those used in this study. SK-BR-3 were cultured in McCoy's 5a medium supplemented with L-glutamine and 10\% FBS. MCF-7 was grown in MEM medium supplemented with Lglutamine, non-essential aminoacids, 10\% FBS and 0.01 $\mathrm{mg} / \mathrm{ml}$ bovine insulin. Fibroblasts were cultured in DMEM, supplemented with L-glutamine and 10\% FBS. Other normal and neoplastic cell lines were cultured according to the conditions recommended by the ATCC. Hybridoma clones were produced and cultured according to previously described techniques [25].

\section{Antibody characterization}

The isotype of human Abs was determined by ELISA using murine anti-human isotype-specific MAbs to $\mu-, \gamma-, \kappa-$ and $\lambda$-chains (Sigma, USA) and goat anti-mouse Ig $(25 \mu \mathrm{g} /$ $\mathrm{mL}$ ) conjugated to peroxidase and absorbed with human Ig.

\section{Immunocytochemistry and immunohistochemistry}

Cells were plated on ethanol pre-treated cover slips (Fisher, USA) and placed in 6-well plates (Falcon, USA) in culture medium. After 24 hours the cover slips with attached cells were repeatedly washed in PBS and fixed in ethanol. Following fixation and repeated washes, cover slips were incubated with the primary and secondary antibodies according to standard protocols, stained with propidium iodide $1 \mu \mathrm{g} / \mathrm{ml}$ and analyzed by confocal fluorescent microscopy using a Zeiss Axiovert 100 TV microscope and Zeiss software. For immunohistochemistry randomly selected $5 \mu \mathrm{m}$ thick sections of paraffin 
embedded breast cancer tissue were used. Endogenous peroxidase activity was blocked by incubation of slides in $3 \% \mathrm{H}_{2} \mathrm{O}_{2}$ in methanol. Following washing, tissue slides were blocked with 5\% normal goat serum in PBS. Monovalent Fab fragments of goat anti-human IgM+IgG (Jackson Immunoresearch Laboratories, Inc.), in blocking solution, was then applied for secondary blocking. After 3 washes in PBS, the human monoclonal antibody was applied at an approximate concentration of $5 \mathrm{ug} / \mathrm{ml}$. The slides were then washed and incubated with a second FITC conjugated antibody to human $\kappa$-light chains (Sigma, USA) and propidium iodide at $1 \mu \mathrm{g} / \mathrm{ml}$. Following a few washes, mounting medium (Biomeda, USA) and cover slips were applied and sections were analyzed by standard fluorescent microscopy.

\section{Western blotting}

Cells were lysed with freshly prepared ice cold lysis buffer [20 mM Tris-HCl, pH 7.6, 420 mM NaCl, 0.25\% NP40, 2 $\mathrm{mM}$ phenylmethylsulfonyl fluoride, $1 \mathrm{ug} / \mathrm{ml}$ leupeptin, $250 \mathrm{U} / \mathrm{ml}$ Trasylol (aprotinin)] and stored at $-80^{\circ} \mathrm{C}$ or used immediately. Protein concentration was determined with the BioRad Protein Detection Reagent (BioRad). Tissue samples were mechanically homogenized on ice, spun down at $3000 \mathrm{~g}$ for $30 \mathrm{~min}$ at $4{ }^{\circ} \mathrm{C}$ and the lower (non lipid) phase was used for further analysis.

Equal amounts of protein were separated on 10\% SDS polyacrylamide gels and either Coomassie blue or silver stained according to established techniques [27]. Following electrophoresis, the proteins in the gel were transferred to a nitrocellulose membrane using a variation of the methods of Towbin [28] and Burnette [29], and following blocking, probed with relevant primary and HRPconjugated secondary antibody. Membranes were processed using an enhanced chemiluminescence kit (ECL, Amersham), and visualized on Kodak BioMax MR-1 film. The immunoblotting with recombinant GIPC1 protein was carried out as previously described [26].

\section{Binding of 125 |-labeled monoclonal antibody to SK-BR-3 cells and Scatchard analysis}

Antibody 27.F7 was labeled with Na-125I (specific activity $17.4 \mathrm{mCi} / \mathrm{mg}$ ) (New England Nuclear, MA, USA) using Iodogen as previously described [30]. The resulting specific activity of $125 \mathrm{I}-27 . \mathrm{F} 7$ was $(100 \mathrm{mCi} / \mathrm{mmol})$. SK-BR-3 cells were grown in 24-well plates supplemented with DMEM media with $10 \%$ FCS and used in these experiments at subconfluent phase at a density of $2 \times 10^{5}$ cells per well. Cell monolayers were suspended with trypsin, cooled to $4^{\circ} \mathrm{C}$ by placing them on ice and washed twice with PBS containing 1\% BSA (Sigma, USA). The cells (50,000 cells per sample) were blocked with $1 \%$ BSA-PBS for 1 hour at $4^{\circ} \mathrm{C}$ followed by incubation with ${ }^{125}$ I-27.F7 (approx. $10^{5} \mathrm{cpm}$ per sample) in the presence of increas- ing concentrations of cold unlabeled 27.F7 (ranging 0.1 $200 \mathrm{ng} / \mathrm{ml}$ ) for 1 hour at $4^{\circ} \mathrm{C}$. After incubation the samples were applied to Millipore filters using Millipore 96well membrane plates (Millipore, USA). The wells were broken off and counted individually in a Cobra $\gamma$-counter (Hewlett Packard, USA). Maximum binding, $\mathrm{B}_{\max ^{\prime}}$ was determined by incubating varying numbers of cells (ranging from $1.25 \times 10^{4}$ to $32 \times 10^{5}$ cells) with radiolabeled 27.F7 antibody. Nonspecific binding of the tracer was determined in the presence of an excessive amount of unlabeled antibody $(500 \mu \mathrm{g} / \mathrm{ml})$ and was generally less than $5 \%$ of maximum binding. All experimental measurements of $K_{a}$ and the number of antigen targets per cell were done in triplicate. Analysis of the data was performed according to previously described methods [3133].

\section{Antigen identification}

RNA was purified from SK-BR-3 cells according to standard protocols. Preparation of mRNA was performed by oligo dT chromatography with a kit from Stratagene (La Jolla, CA). A lambda phage expression library was prepared in lambda ZAP (Stratagene, La Jolla, CA) and plaque lifts were screened with human monoclonal 27.B1 and 27.F7 according to previously described methods $[21,34]$. Phage plaques that were positive on the first screened were picked and two rounds of plaque purification was performed to ensure that they were true positives. Positive lambda phage clones were autoexcised according to the protocol provided by Stratagene, grown as plasmids according to standard protocols and sequenced to identify the cDNA inserts.

\section{Northern blot analysis}

Total cellular RNA was isolated by the Guanidinium/Phenol extraction method and Northern blotting was performed as previously described [35,36]. Briefly, $15 \mu \mathrm{g}$ of RNA is denatured and electrophoresed in a 1.2\% Agarose gel along with $3.5 \%$ formaldehyde, transferred to a nylon membrane and hybridized sequentially with ${ }^{32}$ P-labeled cDNA probes. The GIPC1 cDNA fragment that we isolated using SEREX technology was used for the gene specific probe and a cDNA fragment of the GAPDH gene was used as an internal control to normalize expression. Following hybridization, the filters were washed and exposed for autoradiography.

\section{Results}

\section{A native fully human autoantibody to breast cancer identifies a cancer-associated antigen that localizes to the cytoplasm and membrane}

We previously described the construction of a unique fusion Partner cell line, MFP-2, and its use for the immortalization of both human peripheral blood and lymph node B-lymphocytes [24,25]. MFP-2 was employed for 
the generation of hybridoma cells from lymphocytes of breast cancer patients that produce autologous anti-breast cancer specific antibodies. The results of that study are described elsewhere [25]. One of these native human monoclonal antibodies, designated 27.B1 (IgM, k), was chosen for further study. It demonstrated an intensely positive reactivity with two human breast cancer cell lines, SK-BR-3 and MCF-7 and no reaction with normal diploid primary human fibroblasts as tested by cELISA (In cELISA whole cells are used in place of a purified antigen as in ELISA) [25]. Confocal microscopy with 27.B1 demonstrated the presence of the target antigen throughout the cytosol and in addition staining of the membrane was especially strong (see Figure 1). Furthermore, 27.B1 stained both primary and metastatic breast cancer with a high specificity and sensitivity [25]. These results along with a more detailed immunocytochemical and immunohistochemical analysis are described elsewhere [25].

\section{The target antigen for monoclonal antibodies 27.BI and} 27.F7 is a $42 \mathrm{kDa}$ protein

To identify the size of the 27.B1 target protein, Western blot analysis was performed using whole cell lysates from different cell lines and tissues. Cell lysates prepared from human breast cancer, normal breast tissue, human prostate cancer and two human fibroblast cell lines were run on PAGE under reducing conditions and blotted with fhMAb 27.B1. The antibody reacted with a protein band of approximately $42 \mathrm{kDa}$ molecular weight that is detectable primarily in breast cancer cells (see Figure 2-A). There was no detectable immunoreactivity with the human fibroblasts' lysates and prostate cancer cell line LnCaP whereas only traces of immunoreactivity were detected to prostate cancer cell lines PC3 and DU-145 (data not shown). The protein band revealed by $27 . \mathrm{B} 1$ appeared as doublet with a dominant band that migrates slower on a gel. The doublet pattern was not the same in all 27.B1 positive cells; MCF-7 cells displayed the higher molecular weight band in much greater abundance, whereas SK-BR3 showed both bands in more equivalent intensity (data not shown). Western blot analysis of the same cell lysates under non-reducing conditions displayed no difference in staining pattern, indicating that accessibility of the epitope bound by 27.B1 is disulfide bond independent and likely conformation independent.

Interestingly, we determined that another antibody, 27.F7, which was previously identified as binding breast cancer cells and tissue with high specificity and sensitivity [25], identified the same $42 \mathrm{kDa}$ molecular weight doublet as 27.B1. Furthermore, this antibody detected the bands in the doublet with the same variability in different cell lines as 27.B1. To test the epitope specificity of the two antibodies one of them, 27.F7 was radiolabeled with ${ }^{125}$ I and competitive Western blotting was performed with

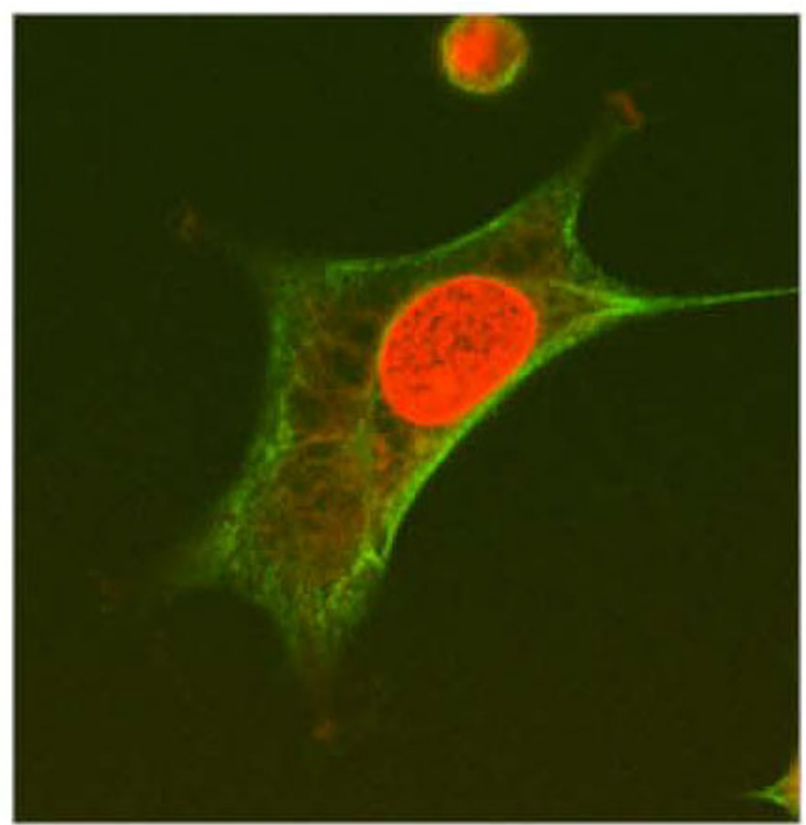

\section{SK-BR-3}

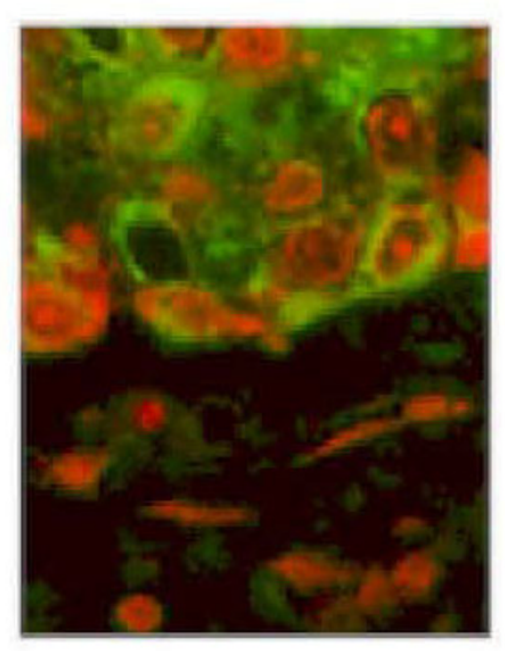

\section{Breast cancer tissue}

Figure I

Human monoclonal 27.BI stains the membrane and cytosol. Staining of SK-BR-3 cells and breast cancer tissue was performed with human monoclonal 27.BI. Staining of the SK-BR-3 breast cancer cell line was analyzed by confocal microscopy and indicates that the target antigen is present in the membrane and cytoplasm. Staining of human breast cancer tissue was analyzed by standard fluorescent microscopy. 
A

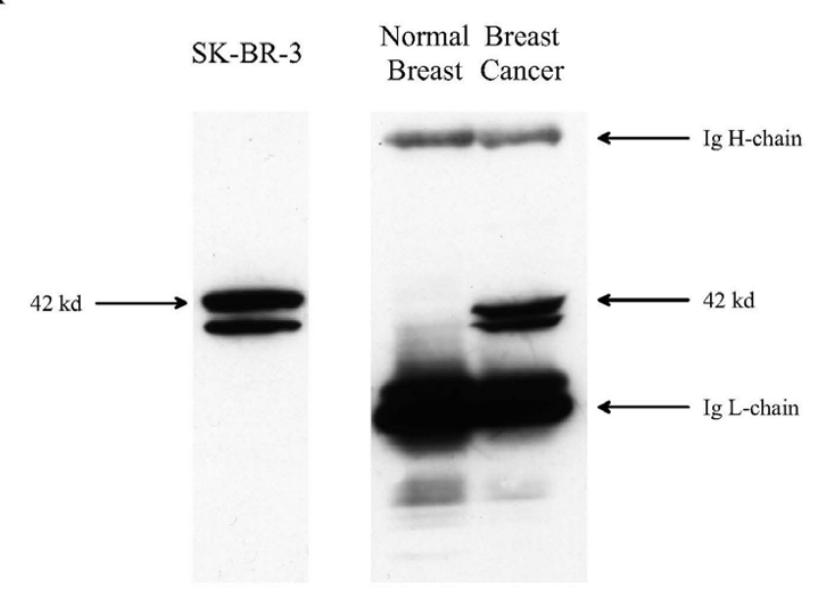

B

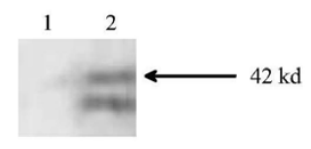

Figure 2

The target antigen for human monoclonal 27.B I is a GIPCI protein. A. The target antigen for monoclonal 27.B I in SK-BR-3 cells, breast cancer tissue and normal breast tissue was identified by Western blot and is displayed. Human Ig $\mathrm{H}$ and $\mathrm{L}$ chains are present in the tissue and are recognized by the secondary anti-human antiserum. The target antigen is detected as a doublet in both the breast cancer tissue and SK-BR-3 cell line but is not detected in normal breast tissue. Both bands in the doublet are present in all breast cancer cell lines analyzed by Western blot but their intensity is variable. B. Immunoblotting with 27.BI antibody of total cell lysates prepared from SK-BR-3 cells. 27.BI antibody was preincubated with recombinant GIPCI protein prior to blotting (lane I), and compared to non-preincubated control (lane 2).

both antibodies (data not shown). Pretreatment of a SKBR-3 cell lysate blot with unlabeled 27.F7 inhibited binding of 125I-labeled 27.F7, whereas unlabeled 27.B1 antibody did not inhibit binding. This suggests that if these two antibodies are binding the same protein they likely bind different epitopes.

To identify the molecular target(s) for 27.B1 and 27.F7, SEREX technology was applied as previously described $[21,25,34]$ to a cDNA expression library prepared from SK-BR-3 mRNA. Expression clones staining positively with 27.F7 and 27.B1 were selected and the cDNA sequences were found to encode the protein known as GIPC1, following a BLAST algorithm homology search [37]. This protein was previously identified as being involved in the regulation of $\mathrm{G}$ protein signaling [38]. The sequence of the cloned cDNA inserts are identical to the respective sequence reported in GenBank for GIPC1.
To confirm that the $42 \mathrm{kDa}$ band demonstrated in Figure 2-A is indeed GIPC-1, we performed immunoblotting with recombinant GIPC-1 protein (Figure 2-B). For this purpose, 27.B1 antibody was preincubated with a bacterial expressed and refolded recombinant GIPC1 protein prior to blotting (Figure 2-B, lane 1) and compared to non-preincubated control (Figure 2-B, lane 2). These results demonstrate that fhMAb 27.B1 binding to the same $42 \mathrm{kDa}$ band was specifically inhibited by the recombinant protein and this confirmed the specificity of this antibody to the GIPC1 antigen.

\section{Scatchard analysis}

Scatchard analysis of ${ }^{125}$ I-27.F7 binding to SK-BR-3 cells revealed a two-mode pattern of binding, which matches a model with binders of two different avidities (see Figure 3 ) [31]. One type of bound ligand is represented by approximately $20 \%$ of all 27 .F7 targets and binds the antibody with high avidity $\left(\mathrm{K}_{\mathrm{a}}=4.2 \times 10^{11} \mathrm{M}^{-1}\right)$. The second type of ligand binds with a lower avidity $\left(\mathrm{K}_{\mathrm{a}}=3.3 \times 10^{9} \mathrm{M}^{-}\right.$ 1) and constitutes about $80 \%$ of the total antigen molecules. An estimate for the total number of antigen molecules per cell is approximately $3 \times 10^{5}$ target GIPC1 molecules per cell. The identification of two binding avidities may be related to the fact that human monoclonal antibody 27.F7 (and 27.B1) identifies a two band doublet on a Western blot (see Figure 2). This suggests that one of the bands may be a ligand of higher avidity while the second one is of lower avidity. The doublet itself has been previously reported although the reason for two bands

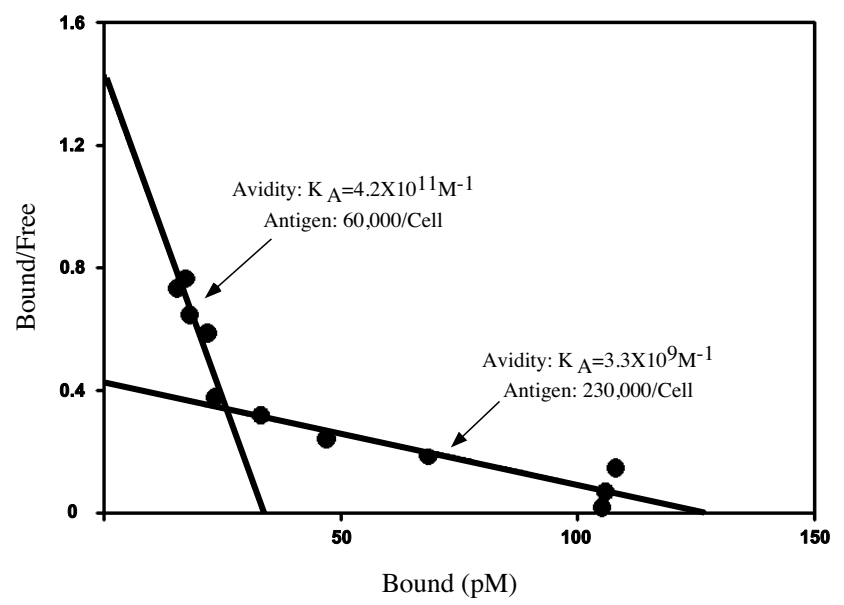

Figure 3

Scatchard analysis of human anti-GIPCI monoclonal antibody on antibody on SK-BR-3 cells. Scatchard analysis of human monoclonal antibody $27 . F 7$ performed on SKBR-3 cells revealed the presence of an antigen target with two affinities. This suggests that two populations of GIPCI molecules exist in these cells and may be related to the protein doublet identified by Western blot analysis in Figure 2. 
has not been determined [38]. It might be explained by an alternative start codon or posttranslational modification.

\section{GIPCI is up-regulated in breast cancer cell lines}

The strong staining by the human anti-GIPC1 monoclonal antibodies, 27.B1 and 27.F7, on breast cancer cell lines and absent staining of normal cells [25] suggests that the protein might be up-regulated. To semi-quantitatively examine gene expression we performed Northern blot analysis to determine if a higher level of GIPC1 specific mRNA was indeed present in the breast cancer cell lines relative to normal cell lines. RNA from a variety of breast cancer cell lines along with non-neoplastic cell lines was blotted and GAPDH expression was monitored as an internal control to normalize expression. The results are depicted in Figure 4. They indicate that breast cancer cells

A

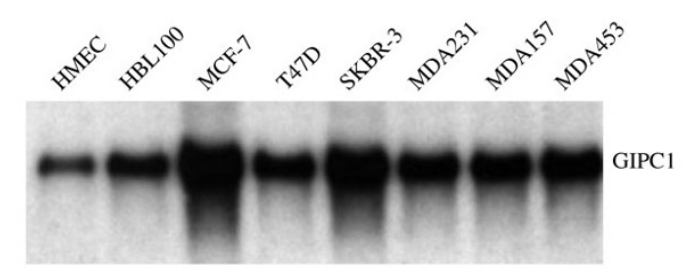

B

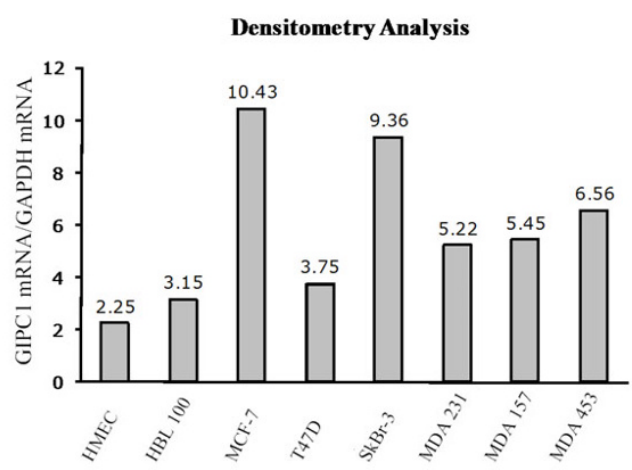

\section{Figure 4}

GIPCI RNA expression analysis in normal and neoplastic cell lines. Panel A: Northern blot analysis of total RNA was performed with RNA samples from a human microvascular endothelial cell line (HMEC), normal breast epithelium cell line HBLI 00 and breast cancer cell lines MCF7, T47D, SK-BR-3, MDA23I, MDAI 57 and MDA453. A probe for the GAPDH gene was used to normalize expression. Panel B: Densitometry analysis of the Northern blot was performed to quantitate the mRNA expression. The data indicates that the GIPCI gene is upregulated in breast cancer cell lines. indeed have increased expression of GIPC1 specific RNA relative to that of normal cell lines.

\section{Discussion and conclusion}

Our studies have determined that GIPC1 is a novel breast cancer associated antigen that is up-regulated in breast cancer cell lines and in malignant tissue from all breast cancer patients tested in this study. In our previous studies [25], we determined that the reactivity of the human monoclonal antibodies 27.B1 and 27.F7 are specific to breast cancer tissue and cells. Our present study demonstrated that these antibodies identify the unique antigen target GIPC1 (GAIP interacting protein, C domain), a PDZ domain containing protein $[38,39]$.

GIPC1 was first described as a PDZ domain protein that binds to the $\mathrm{C}$ terminus of RGS-GAIP (for regulators of $\mathrm{G}$ signaling $-\mathrm{G \alpha}_{\mathrm{i} 3}$ interacting protein) [38]. GAIP itself is considered to be a $\mathrm{G \alpha}_{\mathrm{i} 3}$ regulator, which acts as GTP-ase activating protein switching $\mathrm{G \alpha}_{\mathrm{i} 3}$ into an inactive mode [40-45]. Although the functional pathway of $\mathrm{G \alpha}_{\mathrm{i} 3}$ is apparently vesicular trafficking, with GAIP serving as its regulator, the physiological relevance of the interaction between GIPC1 and GAIP is been actively investigated [46-53].

With respect to breast tissue, the recognition by $27 . \mathrm{B} 1$ and 27.F7 of GIPC1 is strictly limited to neoplastic cells. Furthermore, the subcellular localization of the bound antibodies in the cell membrane and cytoplasm is consistent with what has been previously described for GIPC1 localization [46]. Taken together, our findings suggest that the up-regulation of GIPC1 is cancer cell specific. Although 27.B1 does not detect any protein by FACS or Western blot analysis in normal cells and tissues it is likely below the level of detection since GIPC1 is likely involved in many diverse cellular processes $[47,49-55]$.

GIPC1 plays a role in mediating the assemblage of molecules involved in signaling transduction pathways [53]. As such, these molecules are involved in protein-protein interactions and likely modulate the activity of their targets [53]. Proteins containing PDZ domains, and the interactions that they mediate, may be involved in a wide variety of signal transduction cascades including interaction with receptors, adhesion molecules, ion channels, gap junctions, cytoskeleton proteins and other vital proteins, such as Fas $[48-54,56]$. Moreover, GIPC1 appears to be a highly conserved protein. In rodents it regulates distribution of M-Sem-F, a neuronal membrane-associated protein and binds to a glucose transporter protein, GLUT1 $[57,58]$. It is tempting to speculate on the role of overexpressed GIPC1 in binding to a glucose transporter protein with the subsequent influx of glucose supporting growth of tumor cells. Of course, other proteins may be 
linked to GIPC1 function in cancer cells; this is currently under investigation in our laboratory.

Research of cancer-associated antigens is an extremely important pursuit. Identification of these antigens can provide insight into the cause of a malignancy, identify targets for immunotherapy and immunodiagnostics [26] as well as lead to the development of new cancer vaccines. Previous studies on natural monoclonal autoantibodies from cancer patients did not describe the target antigens $[59,60]$. Our studies demonstrate that by combining the "immunoprospecting" of cancer autoantibodies and SEREX technology discovery of target antigens for monoclonal cancer autoantibodies can be accomplished. In conclusion, our studies revealed that GIPC1 is a novel cancer-associated antigen; its role in carcinogenesis, however, needs further clarification. It also needs to be clarified whether GIPC1 is a specific breast cancer-associated antigen or it is overexpressed in other malignant diseases as well.

\section{Competing interests}

The authors declare that they have no competing interests.

\section{Authors' contributions}

SR carried immunochemical and biochemical studies and organized all the data for the manuscript; MS carried the molecular biology experiments and performed SEREX for identification of the antigen; GK developed hybridoma clones producing specific monoclonal antibody; VY performed flow cytometry and Western blot studies for confirmation of the antigen identity; CL did cell culture work related to cloning and selection of antibody-producing clones; AE, LO and GLC provided an expert clinical information on breast cancer and contributed to the interpretation of data and consideration of potential applications; LL and IT are senior co-investigators who conceived the study, developed its design participating in its coordination and drafting the manuscript. All authors read and approved the final manuscript.

\section{Acknowledgements}

We would like to thank Marina Tashker and Ekaterina Hahiashvili for excellent technical assistance.

This project was supported by American Society Grant and the Department of Medicine at Columbia College of Physicians and Surgeons (SR, GK, AE, IT); the grant form Ludwig Cancer Institute (MS and LO); The Morningside Foundation (GC) and Research Development Grant from BGU of Beer Sheva, Israel (VY, CL and LL).

\section{References}

I. Spadaro M, Lanzardo S, Curcio C, Forni G, Cavallo F: Immunological inhibition of carcinogenesis. Cancer Immunol Immunother 2004, 53(3):204-216.

2. Pardoll D: Does the immune system see tumors as foreign or self? Annu Rev Immunol 2003, 2 1:807-839.
3. Drake CG, Jaffee E, Pardoll DM: Mechanisms of immune evasion by tumors. Adv Immunol 2006, 90:5I-8I.

4. Adair SJ, Carr TM, Fink MJ, Slingluff CL Jr., Hogan KT: The TAG family of cancer/testis antigens is widely expressed in a variety of malignancies and gives rise to HLA-A2-restricted epitopes. J Immunother 2008, 3 I (I):7-I7.

5. Akcakanat A, Kanda T, Koyama Y, Watanabe M, Kimura E, Yoshida Y, Komukai S, Nakagawa S, Odani S, Fujii H, Hatakeyama K: NY-ESOI expression and its serum immunoreactivity in esophageal cancer. Cancer Chemother Pharmacol 2004, 54(I):95-100.

6. Fossa A, Berner A, Fossa SD, Hernes E, Gaudernack G, Smeland EB: NY-ESO-I protein expression and humoral immune responses in prostate cancer. Prostate 2004, 59(4):440-447.

7. Jager E, Jager D, Knuth A: Strategies for the development of vaccines to treat breast cancer. Recent Results Cancer Res 1998, I 52:94- 102.

8. Knuth $A$, Jager $D$, Jager $E$ : Cancer immunotherapy in clinical oncology. Cancer Chemother Pharmacol 2000, 46 Suppl:S46-5I.

9. Korangy F, Ormandy LA, Bleck JS, Klempnauer J, Wilkens L, Manns MP, Greten TF: Spontaneous tumor-specific humoral and cellular immune responses to NY-ESO-I in hepatocellular carcinoma. Clin Cancer Res 2004, I 0( I3):4332-434I.

10. Parmigiani RB, Bettoni F, Grosso DM, Lopes A, Cunha IW, Soares FA, Carvalho AL, Fonseca F, Camargo AA: Antibodies against the cancer-testis antigen CTSP-I are frequently found in prostate cancer patients and are an independent prognostic factor for biochemical-recurrence. Int $J$ Cancer 2008, I 22( I 0):2385-90.

II. McDermott RS, Beuvon F, Pauly M, Pallud C, Vincent-Salomon A, Mosseri V, Pouillart $P$, Scholl SM: Tumor antigens and antigenpresenting capacity in breast cancer. Pathobiology 2002, 70(6):324-332.

12. Cook-Bruns N: Retrospective analysis of the safety of Herceptin immunotherapy in metastatic breast cancer. Oncology 200I, 6 I Suppl 2:58-66.

13. Chen VW, Ruiz B, Killeen JL, Cote TR, Wu XC, Correa CN: Pathology and classification of ovarian tumors. Cancer 2003, 97(10 Suppl):2631-2642.

14. Rabassa ME, Croce MV, Pereyra A, Segal-Eiras A: MUCI expression and anti-MUCI serum immune response in head and neck squamous cell carcinoma (HNSCC): a multivariate analysis. BMC Cancer 2006, 6:253.

15. Lambeck A, Leffers N, Hoogeboom BN, Sluiter W, Hamming I, Klip $H$, ten Hoor $K$, Esajas $M$, van Oven M, Drijfhout JW, Platteel I, Offringa R, Hollema H, Melief K, van der Burg S, van der Zee A, Daemen T, Nijman H: P53-specific T cell responses in patients with malignant and benign ovarian tumors: implications for p53 based immunotherapy. Int J Cancer 2007, I 2 I (3):606-6 I4.

16. Melero I, Hervas-Stubbs S, Glennie M, Pardoll DM, Chen L: Immunostimulatory monoclonal antibodies for cancer therapy. Nat Rev Cancer 2007, 7(2):95-106.

17. Trakht I: Development of human monoclonal antibodies and uses thereof. Volume 040833. The Trustees of Columbia University in the City of New York (New York,NY); 2001.

18. Toubi E, Shoenfeld Y: Protective autoimmunity in cancer (review). Oncol Rep 2007, I 7(I):245-25I.

19. Chen YT: Cancer vaccine: identification of human tumor antigens by SEREX. Cancer JSciAm 2000, 6 Suppl 3:S208-S2 I 7.

20. Pfreundschuh $M$ : Exploitation of the $B$ cell repertoire for the identification of human tumor antigens. Cancer ChemotherPharmacol 2000, 46 Suppl:S3-S7.

2I. Scanlan MJ, Gordan JD, Williamson B, Stockert E, Bander NH, Jongeneel V, Gure AO, Jager D, Jager E, Knuth A, Chen YT, Old LJ: Antigens recognized by autologous antibody in patients with renal-cell carcinoma. Int J Cancer 1999, 83(4):456-464.

22. Tureci O, Sahin U, Zwick C, Neumann F, Pfreundschuh M: Exploitation of the antibody repertoire of cancer patients for the identification of human tumor antigens. Hybridoma 1999, I 8(I):23-28.

23. Kuboshima M, Shimada H, Liu TL, Nakashima K, Nomura F, Takiguchi $M$, Hiwasa T, Ochiai T: Identification of a novel SEREX antigen, SLC2AI/GLUTI, in esophageal squamous cell carcinoma. Int J Oncol 2006, 28(2):463-468.

24. Kalantarov GF, Rudchenko SA, Lobel L, Trakht I: Development of a fusion partner cell line for efficient production of human 
monoclonal antibodies from peripheral blood lymphocytes. Hum Antibodies 2002, I I (3):85-96.

25. Kirman I, Kalantarov GF, Lobel LI, Hibshoosh H, Estabrook A, Canfield R, Trakht I: Isolation of native human monoclonal autoantibodies to breast cancer. Hybrid Hybridomics 2002, 2I(6):405-4I4.

26. Salama O, Herrmann S, Tziknovsky A, Piura B, Meirovich M, Trakht I, Reed B, Lobel LI, Marks RS: Chemiluminescent optical fiber immunosensor for detection of autoantibodies to ovarian and breast cancer-associated antigens. Biosens Bioelectron 2007, 22(7): $1508-1516$.

27. Morrissey $\mathrm{JH}$ : Silver stain for proteins in polyacrylamide gels: a modified procedure with enhanced uniform sensitivity. Anal Biochem 1981, II7(2):307-310.

28. Towbin H, Staehelin T, Gordon J: Electrophoretic transfer of proteins from polyacrylamide gels to nitrocellulose sheets: procedure and some applications. Proc Natl Acad Sci U S A 1979, 76(9):4350-4354.

29. Burnette WN: "Western blotting": electrophoretic transfer of proteins from sodium dodecyl sulfate--polyacrylamide gels to unmodified nitrocellulose and radiographic detection with antibody and radioiodinated protein A. Anal Biochem I 98I, I I 2(2): 195-203.

30. Woltanski KP, Besch W, Keilacker H, Ziegler M, Kohnert KD: Radioiodination of peptide hormones and immunoglobulin preparations: comparison of the chloramine $T$ and iodogen method. Exp Clin Endocrinol 1990, 95(I):39-46.

31. Bobrovnik SA: Ligand-receptor interaction. Klotz-Hunston problem for two classes of binding sites and its solution. J Biochem Biophys Methods 2002, 52(2): I35-143.

32. Klotz IM: A perspective into ligand-receptor affinities using complex numbers. Proc Natl Acad Sci U S A 1993, 90(15):7191-7194.

33. Scatchard G: The attraction of proteins for small molecule ions. AnnNYAcadSci 1949, 51:660-672.

34. Scanlan MJ, Chen YT, Williamson B, Gure AO, Stockert E, Gordan JD, Tureci O, Sahin U, Pfreundschuh M, Old LJ: Characterization of human colon cancer antigens recognized by autologous antibodies. Int J Cancer 1998, 76(5):652-658.

35. Su ZZ, Shen R, O'Brian CA, Fisher PB: Induction of transformation progression in type 5 adenovirus-transformed rat embryo cells by a cloned protein kinase $C$ beta I gene and reversal of progression by 5-azacytidine. Oncogene 1994, 9(4): II I23-II32.

36. Su ZZ, Shi Y, Fisher PB: Subtraction hybridization identifies a transformation progression-associated gene PEG-3 with sequence homology to a growth arrest and DNA damageinducible gene. Proc Natl Acad Sci U S A 1997, 94(I7):9|25-9|30.

37. Altschul SF, Gish W, Miller W, Myers EW, Lipman DJ: Basic local alignment search tool. J Mol Biol I990, 2I 5(3):403-4I0.

38. De Vries L, Lou X, Zhao G, Zheng B, Farquhar MG: GIPC, a PDZ domain containing protein, interacts specifically with the $C$ terminus of RGS-GAIP. ProcNat/AcadSciUSA 1998, 95(2I): I2340-I2345.

39. Lou $X$, Yano H, Lee F, Chao MV, Farquhar MG: GIPC and GAIP form a complex with TrkA: a putative link between $G$ protein and receptor tyrosine kinase pathways. MolBiolCell 200I, 12(3):615-627.

40. De Vries L, Elenko E, Hubler L, Jones TL, Farquhar MG: GAIP is membrane-anchored by palmitoylation and interacts with the activated (GTP-bound) form of $\mathbf{G}$ alpha i subunits. Proc Natl Acad Sci U S A 1996, 93(26): I 5203-15208.

41. De Vries L, Elenko E, McCaffery JM, Fischer T, Hubler L, McQuistan T, Watson N, Farquhar MG: RGS-GAIP, a GTPase-activating protein for Galphai heterotrimeric $\mathbf{G}$ proteins, is located on clathrin-coated vesicles. Mol Biol Cell 1998, 9(5): I I 23- I I 34.

42. Vries D: GAIP is membrane-anchored by palmitoylation and interacts with the activated (GTP-bound) form of $\mathbf{G}$ alpha $i$ subunits. Proc Natl Acad Sci U S A 1996, 93:pp. I 5203-I5208.

43. Lou X, McQuistan T, Orlando RA, Farquhar MG: GAIP, GIPC and Galphai3 are Concentrated in Endocytic Compartments of Proximal Tubule Cells: Putative Role in Regulating Megalin's Function. J Am Soc Nephrol 2002, I3(4):918-927.

44. Sattar AA, Boinpally R, Stromer MH, Jena BP: G(alpha)(i3) in pancreatic zymogen granules participates in vesicular fusion. I Biochem 2002, I 3 I (6):8I5-820.
45. Wylie F, Heimann K, Le TL, Brown D, Rabnott G, Stow JL: GAIP, a Galphai-3-binding protein, is associated with Golgi-derived vesicles and protein trafficking. Am J Physiol 1999, 276(2 Pt I):C497-C506

46. Kedlaya RH, Bhat KM, Mitchell J, Darnell SJ, Setaluri V: TRP I interacting PDZ-domain protein GIPC forms oligomers and is localized to intracellular vesicles in human melanocytes. Arch Biochem Biophys 2006, 454(2): 160-169.

47. Yi Z, Petralia RS, Fu Z, Swanwick CC, Wang YX, Prybylowski K, Sans $\mathrm{N}$, Vicini S, Wenthold RJ: The role of the PDZ protein GIPC in regulating NMDA receptor trafficking. IJ Neurosci 2007, 27(43): I1663-11675

48. Muders MH, Dutta SK, Wang L, Lau JS, Bhattacharya R, Smyrk TC, Chari ST, Datta K, Mukhopadhyay D: Expression and regulatory role of GAIP-interacting protein GIPC in pancreatic adenocarcinoma. Cancer Res 2006, 66(2I): I0264-10268.

49. Varsano T, Dong MQ, Niesman I, Gacula H, Lou X, Ma T, Testa JR, Yates JR 3rd, Farquhar MG: GIPC is recruited by APPL to peripheral TrkA endosomes and regulates TrkA trafficking and signaling. Mol Cell Biol 2006, 26(23):8942-8952.

50. Naccache SN, Hasson T, Horowitz A: Binding of internalized receptors to the PDZ domain of GIPC/synectin recruits myosin VI to endocytic vesicles. Proc Natl Acad Sci U S A 2006, 103(34): | 2735- 12740.

5I. Nunn C, Mao H, Chidiac P, Albert PR: RGS I 7/RGSZ2 and the RZ/ A family of regulators of G-protein signaling. Semin Cell Dev Biol 2006, I7(3):390-399.

52. Wang L, Mukhopadhyay $D, X u X$ : C terminus of RGS-GAIPinteracting protein conveys neuropilin-I-mediated signaling during angiogenesis. Faseb J 2006, 20(9): $1513-1515$.

53. Abramow-Newerly M, Roy AA, Nunn C, Chidiac P: RGS proteins have a signalling complex: interactions between RGS proteins and GPCRs, effectors, and auxiliary proteins. Cell Signal 2006, 18(5):579-59|.

54. Awan A, Lucic MR, Shaw DM, Sheppard F, Westwater C, Lyons SA, Stern PL: 5T4 interacts with TIP-2/GIPC, a PDZ protein, with implications for metastasis. Biochem Biophys Res Commun 2002, 290(3): 1030-1036.

55. Katoh M: GIPC gene family (Review). Int J Mol Med 2002, 9(6):585-589.

56. Liaoyuan: GIPC Interacts with the I-Adrenergic Receptor and Regulates I-Adrenergic Receptor-mediated ERK Activation. The Journal Of Biological Chemistry 2003, 278, No 28(July II):26295-2630I.

57. Bunn RC, Jensen MA, Reed BC: Protein interactions with the glucose transporter binding protein GLUTICBP that provide a link between GLUTI and the cytoskeleton. Mol Biol Cell 1999, 10(4):819-832.

58. Wang LH, Kalb RG, Strittmatter SM: A PDZ protein regulates the distribution of the transmembrane semaphorin, M-SemF. J Biol Chem 1999, 274(20):|4|37-|4|46.

59. Chang HR, Koda K, Chang S, Baird S: AgSKI, a novel carcinoma associated antigen. Cancer Res 1993, 53(5): I I22-I I 27.

60. Koda K, Nakajima N, Saito N, Yasutomi J, McKnight ME, Glassy MC: A human natural antibody to adenocarcinoma that inhibits tumour cell migration. Br J Cancer 1998, 78(10): |3|3-|322.

\section{Pre-publication history}

The pre-publication history for this paper can be accessed here:

http://www.biomedcentral.com/1471-2407/8/248/pre

pub 